\title{
An Application of Different Methodologies for Measuring Poverty in Sharpeville Township
}

\author{
Mmapula Brendah Sekatane \\ School of Economics Science, \\ North-West University, Vanderbijlpark, South Africa \\ E-mail: brendah.sekatane@nwu.ac.za
}

\section{Doi:10.5901/mjss.2013.v4n14p67}

\begin{abstract}
In this article a more accurate methodology for the measurement of absolute poverty, developed by Slabbert, is discussed and compared to the methodology applied by Statistics South Africa in 2000 for the mapping of poverty in South Africa. When both methodologies were applied on the same set of data of Sharpeville Township, the poverty rate measured by the Slabbert method was over three times higher than the poverty rate measured by the Stats SA method (43.1\% compared to 13.7\%). The study shows that both the use of a standard national poverty line as well as proxy incomes could lead to huge inaccuracies in the measurement of poverty. On the whole, the application of a less accurate method to measure poverty was found to lead to lower determined poverty rates. When the poverty rate is lower, it leads to a lower number of households and people that are being determined as poor (5,621 people were determined to be poor in Sharpeville by the Stats SA method, compared to 17,685 by the Slabbert method). This will lead to a totally different kind of action and degree of urgency in the formulation of policies aimed at the alleviation of poverty.
\end{abstract}

Keywords: Poverty, poverty line, Sharpeville, Slabbert, Statistics South Africa

\section{Introduction}

Although reducing poverty is a nearly universal goal among nations and scholars, there is no commonly accepted way of identifying who is poor. Some argue for a multidimensional poverty concept that reflects the many aspects of well-being. In this context, people deprived of social contacts (with friends and families) are described as being socially isolated, and hence poor in this dimension. Similarly, people living in squalid housing are viewed as "housing poor" and people with health deficits as "health poor". Economists tend to prefer a concept of hardship that reflects "economic position" or "economic well-being", somehow measured (Haveman \& Mellikin, 1999:1-2).

Poverty statistics are usually expressed as apparently simple numbers, for example, "One in four children under five lives in a poor family". This simplicity is deceptive. The poverty figures are, in reality, the product of complex layers of pragmatic political and methodological compromises, extending back over three decades (IRP, 1998:1).

Most of the existing literature on the measurement of poverty is concerned with counting the number of people under a certain poverty line. However, the proportion of the population below the poverty line as such does not reflect the intensity of poverty suffered by the poor. The problem is how poor are the poor. They may have income almost near the poverty line or they may not have any income at all. If it is assumed that the deviation of a poor man's income from the poverty line is proportional to the degree of misery suffered by the man, then the sum total of these deviations divided by the number of poor may be considered a desirable measure of poverty (Kakwani, 1980:437).

The range of available poverty measures presents difficulties in deciding which is most appropriate. Goldberg and Pulkingham (1999:5) consider that whatever approach is taken, creating a poverty line requires some "arbitrary decisions". A consumption-based approach requires many decisions about what goods and services are considered in the measure. For example, should different food baskets be used based on age? Should the cost of a haircut be included? Should transportation costs include having a car or, assuming public transportation is available, should monthly public transportation passes be used in measuring the costs or should a certain number of individual fares be used to determine the cost? Similar problems exist for a mixed and equity-based approach. For example, how many percentage points should be added to average expenditures to set the poverty line? Why use only food, clothing, and shelter rather than food, shelter and transportation, which the family expenditure survey shows are the three areas of greatest expenditure for families? Should mean or median income be used in determining the average income? Should 
averages take into account differences based on age (experience) (Goldberg \& Pulkingham, 1999:5-6)?

The reduction of poverty and inequality has been a central concern of South Africa's government since 1994. Yet, quantitative description and analysis in this field have been slow to emerge. The main reason is that evidence had to be built up (mainly by Statistics South Africa (Stats SA)) from a very limited historical base (Simkins, 2000:1). A further problem with the measurement of poverty in South Africa was pointed out by Godsell and Buys (1992:636), namely, the fact that no national definition of poverty exists in South Africa. Much research into poverty in South Africa has used various, mostly international, measurements of poverty with little effort at national contextualisation. Estimates of the levels of poverty in the country therefore vary considerably (Mokoena, 2004:56-57).

In this article a more accurate methodology for the measurement of absolute poverty, developed by Slabbert (1997), is discussed and compared to the methodology applied by Statistics South Africa in 2000 for the mapping of poverty in South Africa (Hirschowitz, 2000). Both methodologies are applied to household survey data obtained in Sharpeville (in August 2004). Sharpeville is one of the Vaal Triangle's townships, located in Emfuleni Local Municipality, in the southern part of Gauteng. The results from the application of the two methodologies are compared and discussed.

\section{Theoretical an Analysis of the Two Methodologies}

Both the methodologies of Slabbert and Stats SA are measuring poverty at household level, making use of income or expenditure data. Poverty is thus defined in absolute terms, as done by the World Bank (1990). Both household income as well as a poverty line is defined. Although both methodologies measure the extent of poverty (headcount index), Slabbert's method lends itself for the measuring of the magnitude of poverty by means of the poverty gap index and Stats SA's method doesn't. An accurate profile of the distribution of the poor below their respective poverty lines can be constructed from the results with Slabbert's method.

\subsection{The methodology used by Statistics South Africa for the measurement of poverty}

In this method, the headcount index is defined as the fraction of the population below the poverty line (Deaton, 1994: 122). The headcount index $(H)$, for a population of $N$ income units with incomes $y_{i}(i=1 \ldots N)$ ranked in ascending order by subscript, $M$ units have incomes equal to or less than $z$, may be defined as follows (Borooah \& McGregor, 1991:359):

Headcount index:

$$
H(y ; z)=M / N
$$

Statistics South Africa's 2001 census questionnaires unfortunately did not make provision for determining the exact income of a household, but could only determine the income of a household within a certain category. Twelve income categories were defined as indicated in the first three columns of Table 1.

Table 1: Ranking households' income for proxy income allocation

\begin{tabular}{|c|c|c|c|}
\hline $\begin{array}{c}\text { Income } \\
\text { category }(\mathrm{i})\end{array}$ & $\begin{array}{c}\text { Lower limit of income range } \\
\left(\mathrm{y} \mathbf{1}_{\mathrm{i}}\right)\end{array}$ & $\begin{array}{c}\text { Upper limit of income range } \\
\left(\mathrm{yu}_{\mathrm{i}}\right)\end{array}$ & $\begin{array}{c}\text { Proxy income value allocated } \\
\left(\mathrm{yp}_{\mathrm{i}}\right)\end{array}$ \\
\hline 1 & 0 & 0 & 0 \\
\hline 2 & 1 & 4800 & 3200 \\
\hline 3 & 4801 & 9600 & 7200 \\
\hline 4 & 9601 & 19200 & 14400 \\
\hline 5 & 19201 & 38400 & 28800 \\
\hline 6 & 38401 & 76800 & 57600 \\
\hline 7 & 76801 & 153600 & 115200 \\
\hline 8 & 153601 & 307200 & 230400 \\
\hline 9 & 307201 & 614400 & 460800 \\
\hline 10 & 614401 & 1228800 & 921600 \\
\hline 11 & 1228801 & 2457600 & 1843200 \\
\hline 12 & 2457601 & 4915200 & 3686400 \\
\hline
\end{tabular}

Source: Own construction, based on information from Stats SA 
To determine the Headcount index, using the Stats SA 2001 Census data, a proxy income value is allocated to each household. The proxy income value of a household $\left(y_{j}\right)$ is zero if the household falls into the first category (where a household has no income). For $\mathrm{i}=1: y p_{i}=0$. For a household falling into the second category, the proxy income is expressed as: $y p_{i}=y u_{i-1}+\left[\left(y u_{i}-y u_{i-1}\right) \times 0.6667\right]$. If the income of a household falls into the third to eleventh categories, the proxy income values allocated are given by: $y p_{i}=y u_{i-1}+\left[\left(y u_{i}-y u_{i-1}\right) \times 0.5\right]$.

As mentioned above, the headcount index is determined by:

$H\left(y_{p} ; z\right)=M / N$

As the headcount index is a limited measure of poverty and does not take into account the degree or magnitude of poverty, usually the poverty gap measure is used in conjunction with the headcount index. The poverty gap measures the average shortfall of the income of the poor from the poverty line The methodology used by Statistics South Africa to determine the headcount index however does not lend itself to determine the poverty gap, as proxy income values are used instead of real income values. Therefore, this measure does not show how far the poor are below the poverty line. According to Callan and Nolan (1991:244) it is clearly rather crude to assume that a household earning R999 per month is in poverty, while the household earning R1000 is not.

According to Ravallion (1998:ix), poverty lines for families of different sizes and compositions, living in different places with different prices, or for different dates, tell what expenditures are needed in each set of circumstances to ensure that the minimum level of living needed to escape poverty is reached. The country-wide method used by Stats SA does not provide for that, therefore it is difficult to formulate policies at local level. Ravallion (1996:2) also testifies to that by saying that the "best practice" in setting a poverty line is to adjust for differences in the prices faced (over time or space, in as much detail as data permits), and household demographics. Statistics based on the mean or aggregate income of the poor are criticised for failing to reflect the distribution of income among the poor (Borooah \& McGregor, 1991:358). According to Ravallion (1996:5), setting poverty lines as a constant proportion of the mean for each subgroup seems very unlikely to deliver poverty comparisons of much relevance to anti-poverty policies, since the implicit welfare indicator loses meaning in terms of absolute levels of living. Policies based on this method could easily miss the poorest of the poor, by anyone's reckoning.

\subsection{The methodology used by Slabbert for the measurement of poverty}

Following the guidelines of the World Bank, Slabbert (1997:47; 2003:38 \& 2004:41) defines a poor household as a household of which the combined income of all its members is less than the Household Subsistence Level (HSL) as determined for the specific household. Potgieter (1980:4) defines the HSL as an estimate of the theoretical income needed by an individual household to maintain a defined minimum level of health and decency in the short term. The HSL is calculated at the lowest retail cost of a basket of necessities of adequate quality. The headcount index is defined as the fraction of the population below the poverty line (Deaton, 1994:122).

Slabbert adapts the headcount index to indicate the fraction of households that fall below their individual poverty lines. The poverty gap usually measures the average shortfall of the incomes of the poor from the poverty line while the poverty gap index measures the extent of the shortfall of incomes below the poverty line. Slabbert adapts the poverty gap index to be a measure of a specific household. According to Hill and Michael (2000:2-3) for any poverty measure to be useable, it must be adjustable over time, across geographic space, and across consumer units of different sizes and structures. Slabbert's method satisfies these conditions.

\section{Application of Methodologies to a Set of Data}

This section outlines a cross-sectional comparative evaluation of the two methodologies (Stats SA's and Slabbert's) on a set of data from Sharpeville (survey data 2004). A total of 174 households (2.1\% of the households) were interviewed in August 2004 (Sekatane, 2004:127). The Stats SA standard poverty line of R800 (2001) was used for this study when applying and comparing the Stats SA method. This poverty line was inflated for 2004 by the CPI from 2002 up to 2004 to get an adjusted poverty line for 2004. The method used by Stats SA was also applied to a 10\% sample of the 2001 Census-data of Sharpeville. The average poverty line for 2001 is determined by taking the average HSL of households in a 10\% sample, and comparing it with the R800 poverty line.

Table 2 presents the results from the application of the two methodologies. The upper part of the table indicates 
the results of the Stats SA's 10\% sample and the lower part indicates the results based on Stats SA's method Slabbert's method on the 2004 survey data. From note 1 in Table 2, the poverty rate based on the Stats SA's 10\% sample is 62.6\%. This poverty rate was determined by compiling a poverty line for each household and comparing it to the midpoint amount of income determined by Stats SA. When comparing the Stats SA 2001 poverty line of R800 to the midpoint amount of income determined by Stats SA, a poverty rate of $51.2 \%$ was determined. This poverty rate is lower $(51.2 \%$ vs. $62.6 \%$ ) than the poverty rate determined by comparing a poverty line for each household with the midpoint amount of income by Stats SA.

With Slabbert's method (using the 2004 survey data) of determining the poverty rate, whereby a poverty line is determined for each household and compared with the total income of that particular household, a poverty rate of $43.1 \%$ was determined for Sharpeville. Using the 2004 survey data a poverty rate of $46.9 \%$ was determined with Slabbert's method by taking the individual poverty line of a household and comparing it to the total expenditure of the household (note 4 in Table 2). With Slabbert's method there is only a slight difference (i.e. 3.8\%) between the poverty rates (43.1\% vs. 46.9\%) determined by using the total income and the one in which total expenditure is used. The Stats SA 2001 poverty line of R800 was inflated to 2004 by the CPI to give a poverty line of R963.73. This poverty line (R963.73) was compared to the actual household income from the 2004 survey data to determine a poverty rate of $15.5 \%$ (note 5 in Table 2). From Table 2, note 6 based on Stats SA's methodology indicates a poverty rate of $24.7 \%$ which was determined by compiling an average poverty line (R1285.07) based on the HSL for each household individually and compared this line to the income of the household.

Table 2: Stats SA's 10\% sample and the 2004 survey data of Sharpeville

\begin{tabular}{|l|l|c|}
\hline \multicolumn{2}{|l|}{ Stats SA's 10\% sample for 2001 } & Percentages \\
\hline Notes & Description & $62.6 \%$ \\
\hline 1 & Poverty rate (2001 HSL \& mid point income) & $51.2 \%$ \\
\hline 2 & Poverty rate (R800 Poverty line \& mid point income) & 2027 \\
\hline 1 & Average poverty gap & Percentages \\
\hline Slabbert's method and Stats SA's method on the 2004 survey data & $43.1 \%$ \\
\hline Notes & Description & $46.9 \%$ \\
\hline 3 & Poverty rate based on Slabbert's method (2004 HSL \& actual household income) & $15.5 \%$ \\
\hline 4 & Poverty rate based on Slabbert's method (HSL \& actual expenditure) & $24.7 \%$ \\
\hline 5 & Poverty rate based on Stats SA's method (R963.73 poverty line \& actual household income) & $15.5 \%$ \\
\hline 6 & Poverty rate based on Stats SA's method (R1285.07 average poverty line \& actual household income) \\
\hline 7 & Poverty rate based on Stats SA's method (R1285.07 average poverty line \& midpoint household income) & $15.5 \%$ \\
\hline 8 & Poverty rate based on Stats SA's method (R963.73 poverty line \& midpoint household income) & $15 \%$ \\
\hline
\end{tabular}

Source: Own construction, based on the 2004 survey data

In note 7 , an average poverty line was compiled for each household individually based on the $2004 \mathrm{HSL}$, and compared to the relevant mid-point of household income category (inflated) to get a poverty rate of 15.5\%. With Stats SA's method there is a great difference (i.e. $9.2 \%)$ between the poverty rates $(24.7 \%$ vs. $15.5 \%)$ determined by comparing an average poverty line to the income of the household and the one in which an average poverty line was compared to the midpoint of household income category.

Applying the Stats SA's method on the 2004 survey data, the R963.73 (inflated R800) poverty line was compared to the 2001 inflated household midpoint income to give a poverty rate of $15.5 \%$ (note 8 in Table 2). The table indicates that when comparing the $2001 \mathrm{HSL}$ with the mid-point income, the poverty rate is $62.6 \%$ but when comparing the poverty line of R800 with the mid-point income the poverty rate decreases to $51.2 \%$. This is higher than the poverty rate determined from the 2004 survey data which is $43.1 \%$. When comparing the HSL to the actual household expenditure the poverty rate increases from $43.1 \%$ to $46.9 \%$. It is evident from these figures that when the inflated poverty line is employed, the poverty rate decreases until it reaches $15.5 \%$. From all these figures one can conclude that when the Stats SA standard poverty line is employed (together with the mean income) the poverty rate decreases and this might be misleading for policy makers.

\section{Demographic Profiling with the Two Methods}


This section analyses the section of the population that has been found to be poor in the 2004 household survey. A number of indicators are used to profile the poor. The purpose is to show the differences between profiling the poor in terms of Stats SA's methodology and in terms of Slabbert's method, as the results are useful in determining a strategy to alleviate poverty.

For this study, a poor household was defined as a household of which the combined income of all its members is less than the HSL as determined for the specific household. Poverty is measured in terms of the headcount index and the poverty gap index. The headcount index is defined as the fraction of the population below the poverty line. In this study, the headcount index was adapted to indicate the fraction of households that fall below their individual poverty lines. The poverty gap usually measures the average shortfall of the incomes of the poor from the poverty line while the poverty gap index measures the extent of the shortfall of incomes below the poverty line.

The population in Sharpeville was estimated at 41,031 and the average household size at 4.9, meaning that there were 8,374 households in Sharpeville (Sekatane, 2004:61). The headcount index as calculated from the 2004 survey data for Sharpeville was 0.431 , meaning that from the 8,374 households in Sharpeville, 3,609 households lived in poverty. That means 17,685 people were poor in Sharpeville. The poverty gap index was determined at 0.32 , indicating that on average poor households lacked $32 \%$ of the income to attain a level equal to their poverty line (Sekatane, 2004:61). These figures were determined by employing Slabbert's measure of poverty.

When employing Stats SA's measure of poverty, different results were found. If one considers the poverty rate in note 5 (in Table 2) where the Stats SA's 2001 poverty line of R800 was inflated to 2004 by the CPI to give a poverty line of R963.73 and that poverty line (R963.73) was compared with the actual household income from the 2004 survey data to give a poverty rate of $15.5 \%$, the following can be determined. The population is still estimated to be 41.031 and the average household 4.9, meaning that there were 8,374 households, same as above. However, when the inflated Stats SA's poverty line was used the poverty rate decreased from $43.1 \%$ to $15.5 \%$, meaning that the headcount index decreased from 0.431 to 0.155 . A headcount index of 0.155 means that from the 8,374 households in Sharpeville, 1,299 (determined by multiplying the number of households with the headcount index, i.e. $8,374 \times 0.155=1,299$ ) households lived in poverty. This means that 6,365 (determined by multiplying the average household size with the number of poor households, i.e. $4.9 \times 1,299=6,365$ ) people were poor in Sharpeville. With the Stats SA's methodology the poverty gap index was determined at 0.31 , indicating that on average poor households' lacked $31 \%$ of the income to attain a level equal to their poverty line. The same number of poor households and people can be determined when the poverty rate in notes 7 and 8 (in Table 2) are used, since the poverty rate is the same as in note 5 (in Table 2).

If one considers the poverty rate in note 6 (in Table 2), where an average poverty line (R1285.07) was compiled based on the HSL's for each household individually, and compared with the income of each household in the 2004 survey to determine a poverty rate of $24.7 \%$, the following can be determined. The population is still estimated to be 41,031 and the average household 4.9 , meaning that there were 8,374 households, same as above. A poverty rate of $24.7 \%$ means that the headcount index decreased from 0.431 to 0.247 . A headcount index of 0.247 means that from the 8,374 households in Sharpeville, 2,068 (determined by multiplying the number of households with the headcount index, i.e. $8,374 \times 0.247=2,068$ ) households lived in poverty. This means that 10,133 (determined by multiplying the average household size with the number of poor households, i.e. $4.9 \times 2,068=10,133$ ) people were poor in Sharpeville in 2004.

The figures above show that when the Stats SA methodology is employed, the poverty rate is lower than the one determined by Slabbert. When the poverty rate is lower it leads to a low number of households (e.g. 1,299 poor households with a poverty rate of $15.5 \%$ compared to 3,609 poor households with a poverty rate of $43.1 \%$ ) and people that are poor being determined, and this will mislead policy makers as it does not to reflect the true state of affairs of the inhabitants of the township/squatter areas of Sharpeville with regard to poverty. The Stats SA methodology does not accurately determine the poor population as a standard poverty line is used together with a midpoint amount of income determined by Stats SA. In doing that, the Stats SA's methodology does not reflect the intensity of poverty suffered by the poor. The problem is how poor are the poor? The methodology used by Slabbert proves to be more accurate, as real income values are used (i.e. whereby a poverty line for each household is determined and compared with the total income for that household) and can in addition determine the depth of poverty (the poverty gap)).

Figures 1 and 2 give the distribution of the poor households' income as a percentage of their specific HSL. Figure 1 is based on Slabbert's method, which was determined by taking each sample household's HSL and comparing it with its own income. Figure 2 is based on Stats SA's method which was determined by taking an average HSL and comparing it with the households' midpoint incomes. If a household income is above the poverty line, the household falls in the income/HSL category above 100\%. An increase in the number of households below the poverty line indicates an 
increase in the proportion of the poor population. Slabbert (2003:13) points out that "if most households earn 90 - 100\% of their own HSL, this would indicate that poverty is not very severe". In line with this assertion, Figure 1 shows that $25.3 \%$ of all households in Sharpeville had an income of less than $50 \%$ of their HSL compared to $24.4 \%$ in Figure 2. From this information it means that poverty is less severe when applying the Stats SA methodology than when applying Slabbert's method.

Figure 1: Poor Households and their HSL ratios in sharpeville - slabbert's method

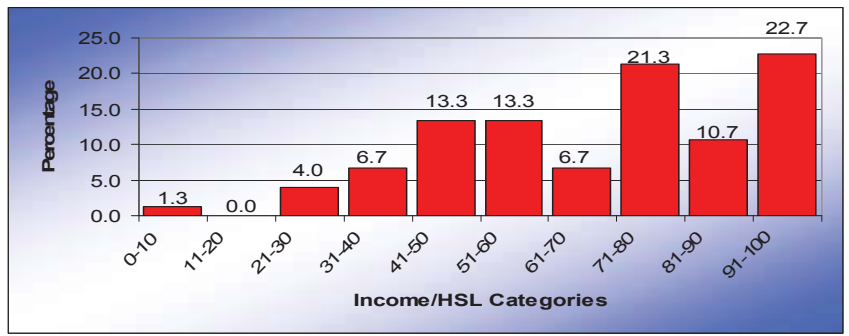

Source: Survey data, 2004

Figure 1 applies to the 3,609 households that lived in poverty and 17,685 people that were poor in Sharpeville. According to Figure 2,1,299 households lived in poverty, meaning that 6,365 people were poor in Sharpeville. There is a difference of 2,310 households that were poor and 11,320 people that lived in poverty between the two figures. With the Stats SA's method the number of poor households and people was very low.

Figure 2: Poor Households and their HSL ratios in sharpeville - stats sa's method

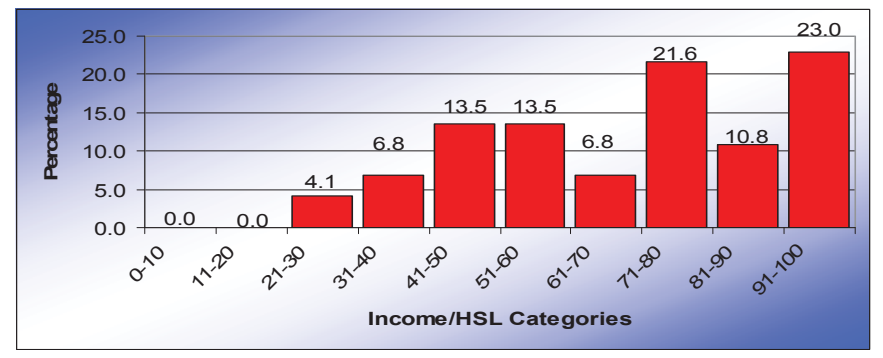

Source: Survey data, 2004

\section{Household Attitude Towards Income Revelation}

Stats SA's 2001 Census questionnaires did not make provision for determining the exact income of households, but only determined the income of households within a certain category. The question that this study raises around this practice by Stats SA is: Why not ask people/households their exact income in the census surveys? Hence a sample of 50 people/households were interviewed in Sharpeville (in the 2006 household survey) by means of questionnaires to determine the attitude people have towards giving their exact income compared to indicating a category. From the 2004 survey data it was found that from the 174 households, 75 households were poor. The sample of 50 people/households that were interviewed (in the 2006 household survey) for the attitude that people/households have towards revealing their income was randomly selected from the 174 households that were interviewed in 2004 (25 households from the poor population and the other 25 from the non-poor population). The 2006 household surveys concerning people's attitude towards revealing their income indicated the followings:

- Poor households:

- $84 \%$ of the respondents felt comfortable revealing their income and $16 \%$ felt uncomfortable.

- $64 \%$ of the respondents preferred giving their exact income than giving their income instead of a category, whereas it is the other way round for the remaining $36 \%$ 
- Non poor households:

- $76 \%$ of the respondents felt comfortable with revealing their income, while $24 \%$ felt uncomfortable.

- $76 \%$ of the respondents preferred giving their exact income than giving their income instead of a category, while the remaining $24 \%$ preferred giving their income in terms of a category against giving it in terms of an exact amount.

From the income revelation attitude data, it is clear that people/households (both poor and non-poor) did not mind revealing their exact income. It was also indicated that the main thing that made people/households unwilling to reveal their income in terms of a category was because they were involved in the informal sector where income is unstable. Based on this information one can conclude that there is no reason for Stats SA to only determine a household income within a category.

\section{Conclusion}

A credible measure of poverty can be a powerful instrument for focusing the attention of policy makers on the living conditions of the poor. A poor measure will be misleading. The Stats SA poverty measure that is used country-wide does not accurately identify the poor population, because of inaccurate measuring instruments.

When looking at the results from the two methodologies, one realizes the large difference between them. The following was determined from the Stats SA's 10\% sample:

- Based on the Stats SA's $10 \%$ sample of Sharpeville a poverty rate of $62.6 \%$ was determined by compiling a poverty line for each household and comparing that particular poverty line to the midpoint amount of income determined by Stats SA.

- When comparing the Stats SA 2001 poverty line (R800) with the midpoint income determined by Stats SA, a poverty rate of $51.2 \%$ was determined for Sharpeville.

Table 3 indicates that Slabbert's methodology yields a higher poverty rate for Sharpeville than Stats SA's methodology. Based on Slabbert's method, when the individual households' poverty line was compared with the total income of that household, a poverty rate of $43.1 \%$ was determined. And when the individual households' poverty line was compared with the total expenditure of that household, a poverty rate of $46.9 \%$ was determined. With Stats SA's methodology, a poverty rate of $15.5 \%$ was determined by taking an average poverty line and comparing it with the households' midpoint incomes. And when the average poverty line was compared with the actual household income, a poverty rate of $24.7 \%$ was determined.

Table 3: Comparing the results of the two methodologies (Stats SA's and Slabbert's)

\begin{tabular}{|l|c|c|c|c|}
\hline \multicolumn{1}{|c|}{ Methodology } & Poverty rate & Headcount index & Poor households & Poor people \\
\hline Slabbert (based on total income) & $43.1 \%$ & 0.431 & 3,609 & 17,685 \\
\hline Slabbert (based on total expenditure) & $46.9 \%$ & 0.469 & 3,927 & 19,242 \\
\hline Stats SA (based on midpoint income) & $15.5 \%$ & 0.155 & 1,299 & 6,365 \\
\hline Stats SA (based on actual income) & $24.7 \%$ & 0.247 & 2,068 & 10,133 \\
\hline
\end{tabular}

Source: Own construction, based on the 2004 survey data

From the table it can be concluded, on a comparative basis that Stats SA's methodology yields a lower number of poor households and people. This does not reflect the true status of the inhabitants of Sharpeville and might be misleading to policy makers. This is due to the fact that the methodology applied by Stats SA country-wide does not lend itself to determine the poverty gap as proxy income values are used instead of real income values. In that way the Stats SA's methodology does not reflect the intensity of poverty suffered by the poor.

\section{References}

Borooah, V.K. \& McGregor, P. (1991). The measurement and decomposition of poverty: an analysis based on the 1985 family expenditure survey for Northern Ireland. Manchester School of Economic and Social Studies, 59(4): 357-365.

Callan, T. \& Nolan, B. (1991). Concepts of poverty and the poverty line. Journal of Economic Surveys, 5(3):243-261.

Deaton, A. (1994). The analysis of household surveys: Microeconomic analysis for development policy. Princeton : Princeton University.

Godsell, B. \& Buys, P. (1992). Growth and poverty - towards some shared goals. In Shrire, R. (ed.) Wealth or poverty? Critical choices 
for South Africa. Cape Town: Oxford University Press.)

Goldberg, M. \& Pulkingham, J. (1999). Defining poverty in Canada. A discussion paper. Canada: SPARC.

Haveman, R. \& Mellikin, M. (1999). Alternatives to the official poverty measure: perspectives and assessment. (Paper presented at a conference: Poverty: improving the definition after thirty years, at the University of Wisconsin on 15-17 April 1999.) Madison. 29p.

Hill, C.J. \& Michael, R.T. (2000). Measuring poverty in the NLSY97. Chicago: University of Chicago.

Hirschowitz, R. (2000). Measuring poverty in South Africa. Pretoria : Statistics South Africa.

IRP (Institute for Research on Poverty). (1998). Revising the poverty measure. Focus, 19(2):1-10, Spring.

Kakwani, N. (1980). On a class of poverty measures. Econometrica, 48(2):437-446.

Mokoena, T.D. (2004). A critical analysis of community-driven development projects aimed at poverty alleviation in Evaton West. Vanderbijlpark: North-West University. (Thesis - PhD.Com.)

Potgieter, J.F. (1980). Background and interpretation of the household subsistence level. Port Elizabeth : Institute for Planning Research.

Ravallion, M. (1996). Issues in measuring and modelling poverty. World Bank policy research working paper no. 1615. Washington D.D.: World Bank.

Ravallion, M. (1998). Poverty lines in theory and practice. LSMS working paper no. 133. Washington D.C.: World Bank.

Sekatane, M.B. (2004). The role of clothing manufacturing co-operatives in job creation and poverty alleviation in Sharpeville. Vanderbijlpark: North-West University. (Dissertation - M.Com.)

Simkins, C. (2000). Introduction. In Hirschowitz, R. Measuring poverty in South Africa. Pretoria: Statistics South Africa. P1-4.)

Slabbert, T.J.C. (1997). Poverty amongst black households in the Vaal Triangle Metropolitan Area: a Micro-analysis. Vanderbijlpark : Vista University. (Thesis - PhD.Com.)

Slabbert, T.J.C. (2003). Bophelong: a socio-economic \& environmental analysis. Research report no.12. Vanderbijlpark: Vaal Research Group.

Slabbert, T.J.C. (2004). An investigation into the state of affairs and sustainability of the Emfuleni economy. Pretoria: University of Pretoria. (Thesis - D.Com.)

STATS SA (Statistics South Africa). (2001). Census 2001: metadata. Pretoria: Statistics South Africa.

Survey Data. (2004). Unpublished results of a survey conducted among households in Sharpeville. Vanderbijlpark.

Survey Data. (2006). Unpublished results of a survey conducted among households in Sharpeville. Vanderbijlpark.

World Bank. (1990). Poverty. Washington DC : Oxford University Press. 